\title{
Simultaneous determination of miconazole and hydrocortisone or mometasone using reversed phase liquid chromatography
}

\author{
Ramzia Ismail El-Bagary a, Ehab Farouk Elkady a, \\ Marwa Hosny Tammam b, and Ayman Abo Elmaaty b,* \\ a Department of Pharmaceutical Chemistry, Faculty of Pharmacy, Cairo University, Cairo, 11562, Egypt \\ b National Organization For Drug Control and Research (NODCAR), Giza, 35521, Egypt \\ *Corresponding author at: National Organization For Drug Control and Research (NODCAR), Giza, 35521, Egypt. \\ Tel.: +2.0122.9257929; Fax: +2.02.24148452. E-mail address: dr ayman3333@yahoo.com (A.A. Elmaaty).
}

\section{ARTICLE INFORMATION}

Received: 24 July 2012

Received in revised form: 11 October 2012

Accepted: 12 October 2012

Online: 31 December 2012

\section{KEYWORDS}

\section{Determination}

Miconazole nitrate

Mometasone furoate

Hydrocortisone acetate

Pharmaceutical preparation

Reversed phase liquid chromatography

\section{Introduction}

Miconazole; 1 -[2,4-dichloro- $\beta$-(2,4-dichlorobenzyloxy) phenethyl]-imidazole (Scheme 1) is an antifungal agent with similar antimicrobial activity to ketoconazole [1]. It is used for treatment of superficial candidiasis, skin infections dermatophytosis and pityriasisversicolor [1].

Hydrocortisone; 11ß,17 $\alpha, 21$-trihydroxypregn-4-ene-3,20dione (Scheme 1) is a principal glucocorticoid hormone [1,2]. It is produced by the adrenal cortex [2] and has been used clinically to treat skin problems such as rashes, eczema and others.

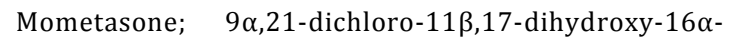
methylpregna-1,4-diene-3,20-dione (Scheme 1) is a corticosteroid used for its glucocorticoid activity [1].

This work is devoted for the simultaneous determination of miconazole in two binary mixtures which are available together in the form of creams.

Literature survey reveals that several analytical methods have been reported for the determination of miconazole nitrate (MIC) alone or in combinations including spectrophotometry [3-11], spectrofluorometry [4] and HPLC [12-30]. Besides, several analytical methods have been reported for the determination of hydrocortisone acetate (HYD) alone or in combination with other drugs including spectrophotometry [31-35], and HPLC [36-45]. MIC and HYD were simultaneously determined by TLC [46] and post column photochemical derivatization HPLC [47]. Also, several analytical methods have been reported for the determination of mometasone furoate
52].<smiles>Clc1ccc(COC(Cn2ccnc2)c2ccc(Cl)cc2Cl)c(Cl)c1</smiles>

Miconazole, MIC<smiles>O=C1C=C2CCC3C(O)CC4C3CCC4(C(=O)CO)C3(CCC(=O)C=C3CC1)C2</smiles>

Hydrocortisone, HYD

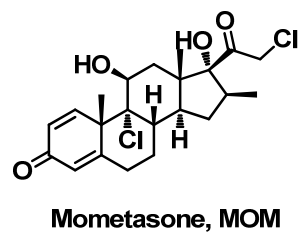

Scheme 1

Furthermore, literature survey reveals, MIC and HYD mixture was determined simultaneously by TLC and post column photochemical derivatization HPLC techniques $[46,47]$ which is tedious and less applicable in quality control work. So, this work can develop quality control of miconazole and hydrocortisone in its semisolid dosage form by using simpler, available and less tedious methods. Thus, the aim of this work 
was to develop simple and validated HPLC method applying C18 columns which are more commonly used. Besides, no previous method has been reported for the simultaneous determination of MIC and MOM. So such method was of interest using a mobile phase with simple composition (acetonitrile: water (Triethylamine $0.2 \%)(70: 30, v: v))$. So quality control of miconazole, hydrocortisone and mometasone was developed and sophisticated and that is one of the most important goals of my quality control work. New methods for simultaneous determination of two or more compounds in the same sample without previous chemical separation are always of interest. Due to wide application and use of RP-HPLC technique, the aim of this study was to develop and validate an alternative reversed-phase liquid chromatographic method for the determination of the binary mixture under investigation applying C18 columns.

\section{Experimental}

\subsection{Instrumentation}

A chromatographic system consisting of Agilent 1200 series (CA, USA); interface equipped with an Agilent quaternary pump G1311A, Agilent UV-visible detector G1314B, an Agilent manual injector G1328B equipped with $(20 \mu \mathrm{L})$ injector loop, an Agilent degasser G1322A and thermo BDS hypersilC18 column ( $5 \mu \mathrm{m}$, 4.6 x $250 \mathrm{~mm}$ ) was used. An Agilent syringe of LC $50 \mu \mathrm{L}$ (CA, U.S.A.) and, ultrasonic processor; (Soniclean 120T, 220/240V, $50 / 60 \mathrm{~Hz}, 60 \mathrm{~W}$, Thebarton SA, Australia) were also used.

\subsection{Materials and reagents}

The pharmaceutical grade MIC was supplied and certified by Camlin Fine Chemicals (Cairo, Egypt) to contain $99.70 \%$. Pharmaceutical grade HYD was supplied and certified by EVA Pharma Company (Cairo, Egypt) with the purity of $99.85 \%$. The pharmaceutical grade MOM with the purity of $99.80 \%$ and Mykotral $\mathrm{H}^{\circledR}$ Cream labeled to contain $20 \mathrm{mg}$ MIC and $10 \mathrm{mg}$ HYD for each 1 gram of cream were provided and manufactured by Sigma Pharmaceutical Industries Company (Cairo, Egypt). Elica $\mathrm{M}^{\circledR}$ Cream manufactured by Jamjom Pharmaceutical Industries Company was labeled to contain 20 $\mathrm{mg}$ of MIC and $1 \mathrm{mg}$ of MOM for each 1 gram of cream. Acetonitrile used was HPLC grade (Scharlau, Spain). Bi-distilled water was produced in-house (Aquatron Water Still, A4000D, UK). Membrane filters of $0.45 \mu \mathrm{m}$ were purchased from Teknokroma (Barcelona, Spain). All other chemicals and reagents used were of analytical grade unless indicated otherwise.

\subsection{Chromatographic conditions}

Chromatographic separation was achieved on a thermo BDS hypercil C18 column ( $5 \mu \mathrm{m}, 4.6 \times 250 \mathrm{~mm}$ ) applying an isocratic elution based on $2.22 \mathrm{mM}$ sodium dihydrogen phosphate:acetonitrile $(55: 45, v: v)$ for mixture 1 and acetonitrile: water $(70: 30, v: v)$ for mixture 2 as mobile phases. Triethylamine $(0.2 \%)$ was added to aqueous phase of the two mobile phases. The flow rate of mobile phase was set to 0.9 $\mathrm{mL} / \mathrm{min}$. The $\mathrm{pH}$ of the mobile phases was adjusted to 3.2 using ortho-phosphoric acid. The injection volume was $20 \mu \mathrm{L}$. Analyses were carried out at ambient temperature and detection was carried out at 215, 245 and $250 \mathrm{~nm}$ for MIC, HYD and MOM, respectively.

\subsection{Standard solutions}

Standard solutions of each of MIC, HYD and MOM were prepared by separately dissolving $20 \mathrm{mg}$ of each drug in 100 $\mathrm{mL}$ mobile phase. Serial dilutions were prepared to get $1,2,4$, $8,10,20,30,40,50,60,70,80,90$ and $100 \mu \mathrm{g} / \mathrm{mL}$ for MIC and
$0.5,1,2,4,8,10,20,40$ and $60 \mu \mathrm{g} / \mathrm{mL}$ for HYD (Mixture 1) and getting $1,2,4,8,10,40,80,120,160$ and $180 \mu \mathrm{g} / \mathrm{mL}$ for MIC and $1,2,4,8,10,20,30,40$ and $60 \mu \mathrm{g} / \mathrm{mL}$ for MOM (Mixture 2).

For mixture 1 further dilutions were made to obtain a concentration rang of $1-100 \mu \mathrm{g} / \mathrm{mL}$ for MIC and $0.5-60.0 \mu \mathrm{g} / \mathrm{mL}$ for HYD. For mixture 2 further dilutions were made to obtain a concentration rang of $1-180 \mu \mathrm{g} / \mathrm{mL}$ for MIC and $1-60 \mu \mathrm{g} / \mathrm{mL}$ for MOM.

\subsection{Sample preparation}

\subsubsection{Mixture 1}

One gram of Mykotral $\mathrm{H}^{\circledR}$ cream was accurately weighed and stirred in $80 \mathrm{~mL}$ of mobile phase with the aid of heat not exceeding $40{ }^{\circ} \mathrm{C}$. The mixture was transferred quantitatively into a $100 \mathrm{~mL}$ volumetric flask and completed to volume with the mobile phase. The mixture was filtered to obtain a sample solution of concentration equivalent to $200 \mu \mathrm{g} / \mathrm{mL}$ for MIC and $100 \mu \mathrm{g} / \mathrm{mL}$ for HYD.

\subsubsection{Mixture 2}

One gram of Elica $\mathrm{M}{ }^{\circledR}$ cream was accurately weighed and stirred in $80 \mathrm{~mL}$ of mobile phase with the aid of heat not exceeding $40{ }^{\circ} \mathrm{C}$. The mixture was transferred quantitatively into a $100 \mathrm{~mL}$ volumetric flask and completed to volume with the mobile phase. The mixture was filtered to obtain a sample solution of concentration equivalent to $200 \mu \mathrm{g} / \mathrm{mL}$ for MIC. The same procedure was repeated starting with $10 \mathrm{~g}$ of the cream to obtain $100 \mu \mathrm{g} / \mathrm{mL}$ for MOM.

\subsection{Procedure}

\subsubsection{Linearity and repeatability}

\subsubsection{Mixture 1}

Accurately measured aliquots of working standard solutions equivalent to $300-800 \mu \mathrm{g}$ for MIC and $40-800 \mu \mathrm{g}$ for HYD were transferred into two series of $10 \mathrm{~mL}$ volumetric flasks and completed to volume with mobile phase .The repeatability of the method was assessed by analyzing a laboratory prepared mixture containing $60 \mu \mathrm{g} / \mathrm{mL}$ for MIC and $30 \mu \mathrm{g} / \mathrm{mL}$ for HYD.

\subsubsection{Mixture 2}

Accurately measured aliquots of working standard solutions equivalent to $100-2000 \mu \mathrm{g} / \mathrm{mL}$ for MIC and 20-600 $\mu \mathrm{g} / \mathrm{mL}$ for MOM were transferred into two series of $10 \mathrm{~mL}$ volumetric flasks and completed to volume the mobile phase. The repeatability of the method was assessed by analyzing a laboratory prepared mixture containing $120 \mu \mathrm{g} / \mathrm{mL}$ for MIC and $6 \mu \mathrm{g} / \mathrm{mL}$ for MOM $(\mathrm{n}=6)$. The precision (R.S.D. \%) for each compound was calculated.

A volume of $20 \mu \mathrm{L}$ of each solution was injected in triplicates into the chromatograph under the specified chromatographic conditions described previously [53]. A calibration curve for each compound was obtained by plotting area under the peak (AUP) against concentration (C).

\subsubsection{Assay of laboratory prepared mixtures, Mykotral $H^{\circledR}$} and Elica ${ }^{\circledR}{ }^{\circledR}$ creams

\subsubsection{Mixture 1}

The procedure mentioned under Section 2.6.1 was repeated using laboratory prepared mixtures equivalent to $10-$ $80 \mu \mathrm{g} / \mathrm{mL}$ MIC and 10-80 $\mu \mathrm{g} / \mathrm{mL}$ HYD (Figure 1). 
Table 1. Assay parameters and method validation obtained by applying HPLC method for the simultaneous determination of miconazole nitrate and hydrocortisone acetate or mometasonefuroate in mixtures *

\begin{tabular}{|c|c|c|c|c|}
\hline \multirow{2}{*}{ Item } & \multicolumn{2}{|l|}{ Mixture 1} & \multicolumn{2}{|l|}{ Mixture 2} \\
\hline & MIC & HYD & MIC & MOM \\
\hline Retention time, min & 2.069 & 5.200 & 2.080 & 5.700 \\
\hline Wavelength of detection, $\mathrm{nm}$ & 215 & 245 & 215 & 250 \\
\hline Range of linearity, $\mu \mathrm{g} / \mathrm{mL}$ & $30-80$ & $4-80$ & $10-200$ & $2-60$ \\
\hline Regression equation & $y=16.4718 x+48.212$ & $y=51.1554 x+6.599$ & $y=17.1994 x+29.186$ & $y=63.5628 x+12.888$ \\
\hline Correlation coefficient $\left(\mathrm{r}^{2}\right)$ & 0.9992 & 0.9995 & 0.9999 & 0.9995 \\
\hline $\mathrm{LOD}(\mu \mathrm{g} / \mathrm{mL})$ & 3.18 & 1.55 & 2.15 & 1.30 \\
\hline $\mathrm{LOQ}(\mu \mathrm{g} / \mathrm{mL})$ & 10.60 & 5.20 & 7.20 & 4.25 \\
\hline $\mathrm{S}_{\mathrm{b}}$ & 0.233 & 0.559 & 0.098 & 0.73 \\
\hline $\mathrm{S}_{\mathrm{a}}$ & 16.426 & 30.777 & 15.150 & 29.800 \\
\hline Confidence limit of the slope & $16.4718 \pm 270.5$ & $51.1554 \pm 1575.5$ & $17.1994 \pm 260.0$ & $63.5628 \pm 1894.0$ \\
\hline Confidence limit of the intercept & $48.2128 \pm 11.23$ & $6.5996 \pm 3.69$ & $29.1865 \pm 2.86$ & $12.8888 \pm 9.40$ \\
\hline Standard error of the estimation & 9.74 & 37.44 & 16.70 & 34.60 \\
\hline Precision, Intra-day \%R.S.D. & 0.97 & 0.11 & 0.644 & 0.93 \\
\hline Precision, Inter-day \%R.S.D. & 0.67 & 0.73 & 0.76 & 0.35 \\
\hline Precision Drug in dosage form & $100.1 \pm 1.49$ & $100.214 \pm 1.01$ & $100.12 \pm 1.30$ & $100.13 \pm 1.46$ \\
\hline Accuracy Drug in laboratory mixture & $100.9 \pm 0.78$ & $100.4 \pm 1.30$ & $99.54 \pm 1.05$ & $100.4 \pm 1.20$ \\
\hline Accuracy Drug added & $100.44 \pm 1.17$ & $99.04 \pm 1.01$ & $101.28 \pm 0.60$ & $100.55 \pm 1.19$ \\
\hline
\end{tabular}

${ }^{*} \mathrm{a}=$ slope, $\mathrm{b}=$ intercept, $\mathrm{S}_{\mathrm{b}}=$ standard deviation of intercept, $\mathrm{S}_{\mathrm{a}}=$ standard deviation of slope.

Table 2. Validation data for the proposed method.

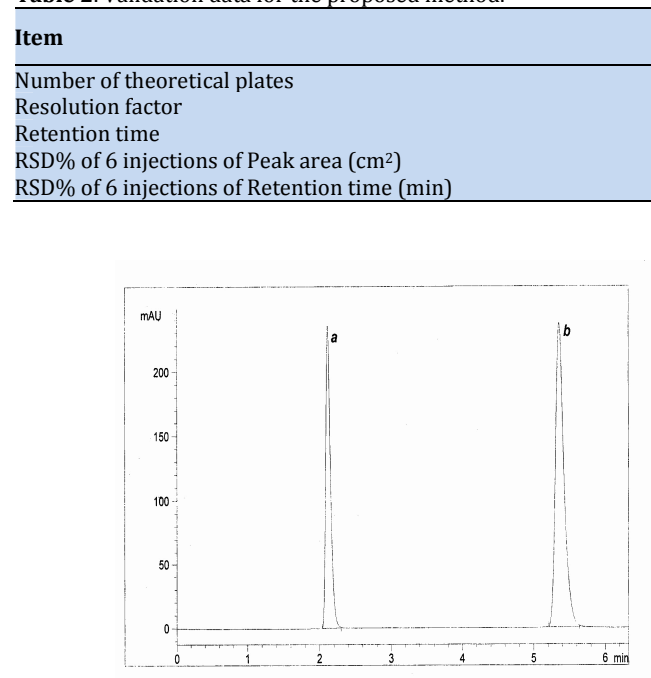

Figure 1. The chromatogram for lab prepared mixture of (a) (MIC) and (b) (HYD) (Mixture 1).

\subsubsection{Mixture 2}

The procedure mentioned under Section 2.6.1 was repeated using laboratory prepared mixtures equivalent to 20 $190 \mu \mathrm{g} / \mathrm{mL}$ MIC and 5-60 $\mu \mathrm{g} / \mathrm{mL}$ MOM (Figure 2).

For the determination of the examined drugs in Mykotral $\mathrm{H}^{\circledR}$ Cream and Elica $\mathrm{M}{ }^{\circledR}$ Cream, the sample solution prepared under Section 2.5 was diluted to prepare different solutions equivalent to $35-80 \mu \mathrm{g} / \mathrm{mL}$ MIC and $25-70 \mu \mathrm{g} / \mathrm{mL}$ HYD (Mixture 1) and $20-190 \mu \mathrm{g} / \mathrm{mL}$ MIC and $15-55 \mu \mathrm{g} / \mathrm{mL}$ MOM (Mixture 2) and injected in triplicate into the chromatograph.

\section{Results and discussion}

A literature survey reveals that MIC and HYD mixture was determined simultaneously by TLC and post column photochemical derivatization HPLC techniques which are tedious and less applicable in quality control work. Thus, the aim of this work was to develop simple and validated HPLC method applying C18 columns which are more commonly used.

A literature survey reveals no analytical work to separate MIC and MOM by HPLC techniques so, the aim of this work was to develop a new, simple, accurate and reproducible LC method for the simultaneous determination of MIC and MOM mixture in a semi-solid pharmaceutical formulation.

\begin{tabular}{llll} 
Mixture 1 & & Mixture 2 & \\
\hline MIC & HYD & MIC & MOM \\
\hline 5443 & 12876 & 1728 & 2339 \\
- & 19.53 & - & 11 \\
1.225 & 1.125 & 1.220 & 1.300 \\
0.970 & 0.110 & 0.644 & 0.930 \\
0.086 & 0.040 & 0.660 & 0.370 \\
\hline
\end{tabular}

For both mixtures, statistical analysis of proposed and reference method reveals that no significant difference at probability of 0.05 . So, ensuring accuracy and precision of proposed method (Table 1).

\subsection{Method development}

For the separation of the examined drugs, various reversed-phase C18 columns, isocratic mobile phase systems were attempted. The mobile phase composition and $\mathrm{pH}$ were studied and optimized.

\subsubsection{Mixture 1}

A satisfactory separation was obtained with a mobile phase composed of $2.22 \mathrm{mM}$ sodium dihydrogen phosphate buffer, acetonitrile $(45: 55, v: v)$, adding triethylamine to the aqueous phase $(0.2 \%)$. The mobile phase was adjusted to $\mathrm{pH}=3.25$ using ortho-phosphoric acid. At higher acetonitrile concentrations, separation was obtained but with excessive tailing for HYD peak. At lower acetonitrile concentrations, high retention times for peaks were obtained. At $\mathrm{pH}=3.25$, optimum resolution with reasonable retention times was observed (Table 2).

\subsubsection{Mixture 2}

A satisfactory separation was obtained with a mobile phase composed of acetonitrile and water (70:30, v:v) adding triethylmine to the aqueous phase $(0.2 \%)$. The mobile phase was adjusted to $\mathrm{pH}=3.2$ using ortho-phosphoric acid. At higher acetonitrile concentrations, separation was obtained but with excessive tailing for MOM peak. At lower acetonitrile concentrations, MOM peaks are resoluted at higher retention time so much time is consumed. At $\mathrm{pH}=3.2$, optimum resolution with reasonable retention time was observed (Table 2).

Quantitative determination based on peak area was achieved with UV detection at 215, 245 and $250 \mathrm{~nm}$ for MIC, HYD and MOM respectively since such drugs give maximum peak absorbance at such wavelengths using UV scanning 
spectrum. So, high sensitivity was obtained for the separated drugs.

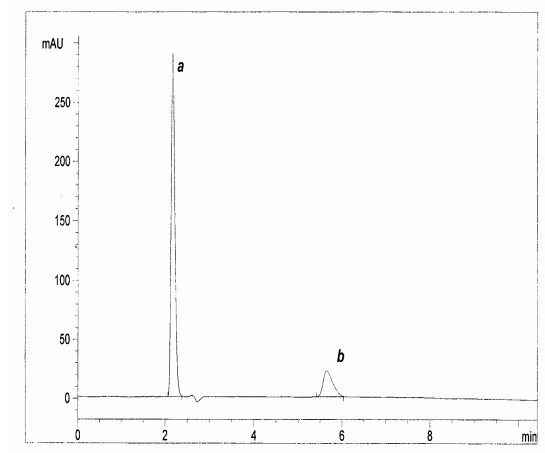

Figure 2. The chromatogram for lab prepared mixture of (a) (MIC) and (b) (MOM) (Mixture 2).

\subsection{Validation of the method}

\subsubsection{Linearity}

Linearity was studied for MIC, HYD and MOM. A linear relationship between area under the peak (AUP) and component concentration (C) was obtained. The regression equation for each drug was also computed (Table 1) in this study, six concentrations for each compound were used. The linearity of the calibration curves were validated by the high value of correlation coefficients (Table 1). The analytical data of the calibration curves including standard deviations for the slope and intercept $\left(S_{b}\right.$ and $\left.S_{a}\right)$ were summarized in Table 1.

\subsubsection{Accuracy}

Accuracy of the results was calculated by \% recovery of laboratory prepared mixtures of 6 different concentrations of the MIC, HYD and MOM and also by standard addition technique for Mykotral $\mathrm{H}^{\circledR}$ and Elica $\mathrm{M}^{\circledR}$ cream. The results obtained including the mean of the recovery and standard deviations are displayed in (Table 1).

\subsubsection{Precision}

Precision was estimated by repeatability. The repeatability of the method was assessed by analyzing a mixture containing 60 and $30 \mu \mathrm{g} / \mathrm{mL}$ for MIC and HYD, respectively $(\mathrm{n}=6)$ (Mixture 1), and analyzing a mixture containing 120 and 6 $\mu \mathrm{g} / \mathrm{mL}$ for MIC and MOM $(\mathrm{n}=6)$, respectively, (Mixture 2). The values of the repeatability (\%R.S.D.) and inter-day and intraday precision (using three different concentrations in triplicates for three days) for the three drugs in two methods are displayed in Table 1.

\subsubsection{Specificity}

Specificity is the ability of the analytical method to measure the analyte response in the presence of interferences. In the present work, the chromatograms of the samples were checked for the appearance of any extra peaks. No chromatographic interference from any of the excipients was found at the retention times of the examined drugs. In addition, the chromatogram of each drug in the sample solution is identical to the chromatogram received by the standard solution at the wavelengths applied. These results demonstrate that there was no interference from other materials in the pharmaceutical formulations and therefore confirm the specificity of the method.

\subsubsection{Range}

The calibration range was established through consideration of the practical range necessary, according to each compound concentration present in the pharmaceutical product, to give accurate, precise and linear results. The calibration range of the proposed HPLC method is given in Table 1.

\subsubsection{Limits of detection and quantification}

Limit of detection (LOD) representing the concentration of analyte at $\mathrm{S} / \mathrm{N}$ ratio of 3 and limit of quantification (LOQ) at which $\mathrm{S} / \mathrm{N}$ is 10 (Table 1). According to ICH recommendations [53], the approach based on the S.D. of the response and the slope were used for determining the detection and quantitative limits. The theoretical values were assessed practically and given in Table 1.

\subsubsection{Robustness}

Robustness is a measure of the method ability to remain unaffected by small variations in the method conditions and is an indication of the method reliability. Robustness was performed by deliberately changing the chromatographic conditions.

Variation of $\mathrm{pH}$ of the mobile phase by \pm 0.2 and its organic strength by $\pm 2 \%$ did not have any significant effect on chromatograms.

The most important parameter to be studied was the resolution factor between the two peaks of MIC and HYD (Mixture 1) and MIC and MOM (Mixture 2). As can be seen in Tables 3-6, good values of the resolution factor were obtained for all these variations, indicating good robustness of the proposed LC method. The flow rate of the mobile phase was changed from 0.9 to $0.8 \mathrm{~mL} / \mathrm{min}$ and $1.0 \mathrm{~mL} / \mathrm{min}$. The organic strength was varied by $\pm 2 \%$ and $\mathrm{pH}$ was varied by \pm 0.2 units. The concentration of sodium dihydrogen phosphate buffer was varied by $2 \%$ (Mixture 1 ) (Table 6 ).

Table 3. The effect of flow rate of the mobile phase on resolution of peaks.

\begin{tabular}{llll}
\hline \multirow{2}{*}{ Item } & \multicolumn{3}{l}{ Flow rate $(\mathbf{m L} / \mathbf{m i n})$} \\
\cline { 2 - 4 } & $\mathbf{0 . 8}$ & $\mathbf{0 . 9}$ & $\mathbf{1 . 0}$ \\
\hline Resolution factor MIC-HYD & 20.54 & 19.52 & 19.19 \\
Resolution factor MIC-MOM & 11.2 & 11.24 & 11.16 \\
\hline
\end{tabular}

Table 4. Influence of organic strength of the mobile phase on resolution of peaks.

peaks.

\begin{tabular}{lllll|}
\hline Concentration vs. organic strength & & & & \\
\hline Mixture 1 & Item, \% & 55 & 53 & 57 \\
& Resolution factor MIC-HYD & 19.61 & 19.87 & 18.42 \\
\hline Mixture 2 & Item, \% & 68 & 70 & 72 \\
& Resolution factor MIC-MOM & 11.96 & 11.19 & 12.04 \\
\hline
\end{tabular}

Table 5. Influence of $\mathrm{pH}$ of the mobile phase on resolution of peaks. pH vs. resolution

\begin{tabular}{ll|lll}
\hline Mixture 1 & Item, $\mathrm{pH}$ & 3.15 & 3.25 & 3.35 \\
& Resolution factor MIC-HYD & 21.71 & 20.64 & 20.18 \\
\hline Mixture 2 & Item, pH & 3.10 & 3.20 & 3.30 \\
& Resolution factor MIC-MOM & 10.93 & 10.93 & 10.00 \\
\hline
\end{tabular}

Table 6. Influence of concentration of sodium dihydrogen phosphate buffer on resolution of peaks.

\begin{tabular}{llll}
\hline Item (Mixture 1) & $0.22 \mathrm{Mm}$ & $2.22 \mathrm{Mm}$ & $4.22 \mathrm{Mm}$ \\
\hline Resolution factor MIC-HYD & 20.20 & 20.15 & 20.03 \\
\hline
\end{tabular}

\subsection{Statistical analysis of the results}

A statistical analysis of the results was obtained by the proposed method. The reference methods were carried out by "SPSS statistical package version 11". 
Table 7. Statistical analysis of the results obtained by the proposed LC method and the reference methods.

\begin{tabular}{|c|c|c|c|c|c|c|c|c|}
\hline \multirow{3}{*}{$\begin{array}{l}\text { Statistical } \\
\text { term }\end{array}$} & \multicolumn{4}{|c|}{ Mixture 1} & \multicolumn{4}{|c|}{ Mixture 2} \\
\hline & \multicolumn{2}{|c|}{ MIC } & \multicolumn{2}{|l|}{ HYD } & \multicolumn{2}{|c|}{ MIC } & \multicolumn{2}{|l|}{ MOM } \\
\hline & HPLC & $\begin{array}{l}\text { Reference } \\
\text { method } * *\end{array}$ & HPLC & $\begin{array}{l}\text { Reference } \\
\text { method } * * *\end{array}$ & HPLC & $\begin{array}{l}\text { Reference } \\
\text { method } * *\end{array}$ & HPLC & $\begin{array}{l}\text { Reference } \\
\text { method } * * * *\end{array}$ \\
\hline Mean & 100.90 & 100.20 & 100.40 & 99.90 & 99.54 & 100.22 & 100.40 & 100.02 \\
\hline S.D. & 0.780 & 0.509 & 1.300 & 0.645 & 1.052 & 0.510 & 1.200 & 0.542 \\
\hline R.S.D. & 0.770 & 0.508 & 1.300 & 0.646 & 1.056 & 0.508 & 1.200 & 0.542 \\
\hline $\mathrm{N}$ & 6 & 6 & 6 & 6 & 6 & 6 & 6 & 6 \\
\hline \multirow{3}{*}{$\begin{array}{l}\text { Variance } \\
\text { t-value } \\
\text { F-value }\end{array}$} & 0.610 & 0.259 & 1.690 & 0.416 & 1.100 & 0.260 & 1.440 & 0.293 \\
\hline & \multicolumn{2}{|c|}{$1.84(2.228)$ * } & \multicolumn{2}{|c|}{$0.85(2.228)^{*}$} & \multicolumn{2}{|c|}{$1.45(2.228) *$} & \multicolumn{2}{|c|}{$0.72(2.228) *$} \\
\hline & \multicolumn{2}{|c|}{$2.35(5.05) *$} & \multicolumn{2}{|c|}{$4.06(5.05) *$} & \multicolumn{2}{|c|}{$4.26(5.05) *$} & \multicolumn{2}{|c|}{$4.91(5.05) *$} \\
\hline
\end{tabular}

* Figures in parentheses are the corresponding values for theoretical $t$ - and F-values at $p=0.05$.

** Reference method for MI using HPLC method according to U.S.P34 [54].

*** Reference method for HY using UV spectrophotometry method according to B.P. 2011 [55].

**** Reference method for MOM using HPLC method according to U.S.P 34 [54].

The significant difference between groups was tested by Ttest and F-test at $p=0.05$ as shown in Table 7. The test ascertained that there was no significant difference among the methods.

\section{Conclusion}

The proposed HPLC method provides simple, accurate and reproducible quantitative analysis for the simultaneous determination of MIC and HYD or MOM in creams. This method was validated as per ICH guidelines [53]. The proposed method is suitable for the quality control determination of the cited drugs in ordinary laboratories

\section{References}

[1]. Reynolds, J. E. F. The extra pharmacopeia, 37th edition, Volume A, 2011.

[2]. O'Neil, M. J. The Merck Index 14th edition, An Encyclopedia of Chemicals, Drugs and Biologicals, 2006.

[3]. Erk, N.; Altun, M. L. J. Pharm. Biomed. Anal. 2001, 25(1), 115-122.

[4]. Khashaba, P. Y.; El-Shabouri, S. R.; Emara, K. M.; Mohamed, A. M. J. Pharm. Biomed. Anal. 2000, 22(2), 363-376.

[5]. Goger, N. G.; Gokcen, L. Anal. Lett. 1999, 32(13), 2595-2602.

[6]. Wrobel, K.; De-la-Garza-Rodriguez, I. M.; Lopez-de-Alba, P. L.; LopezMartinez, L. J. Pharm. Biomed. Anal. 1999, 20(1-2), 99-105.

[7]. El-Shabouri, S. R.; Emara, K. M.; Khashaba, P. Y.; Mohamed, A. M. Anal. Lett. 1998, 31(8), 1367-1385.

[8]. Erk, N. STP. Pharma. Sci. 1996, 6(37), 312-315.

[9]. Chen, B. Zhongguo Yiyao Gongye Zazhi 1993, 24(7), 318-319.

[10]. Cavrini, V.; Di-Pietra, A. M.; Gatti, R. J. Pharm. Biomed. Anal. 1989, 7(12), 1535-1543.

[11]. Cavrini, V.; Di-Pietra, A. M.; Raggi, M. A. Pharm. Acta. Helv. 1981, 56(6), 163-165.

[12]. Huang, Q. X.; Yu, Y. Y.; Tang, C. M.; Peng, X. Z. J. Chromatogr. A. 2010, 1217(21), 3481-3488.

[13]. Moradi, M.; Yamini, Y.; Vatanara, A.; Saleh, A.; Hojati, M.; Seidi, S. Anal. Methods 2010, 2(4), 387-392.

[14]. DeZan, M. M.; Camara, M. S.; Robles, J. C.; Kergaravat, S. V.; Goicoechea, H. C. Talanta 2009, 79(3), 762-767.

[15]. Ali, I.; AboulEnein, H. Y.; Gaitonde, V. D.; Singh, P.; Rawat, M. S. M.; Sharma, B. Chromatographia 2009, 70(1/2), 223-227.

[16]. Zhong, W.; Tang, X.; Wu, Q. J. Yaowu Fenxi Zazhi 2006, 26(9), 13051307.

[17]. Cakar, M.; Popovic, G.; Agbaba, D. J. Aoac. Int. 2005, 88(5), 1544-1548.

[18]. Cirilli, R.; Ferretti, R.; Gallinella, B.; La-Torre, F.; La-Regina, G.; Silvestri, R. J. Sep. Sci. 2005, 28(7), 627-634.

[19]. Aboul-Enein, H. Y.; Ali, I. J. Pharm. Biomed. Anal. 2002, 27(3-4), 441446.

[20]. Aboul-Enein, H. Y.; Ali, I. Chromatographia 2001, 54(3-4), 200-202.

[21]. Aboul-Enein, H. Y.; Ali, I. FreseniusJ. Anal. Chem. 2001, 370(7), 951-955

[22]. Indrayanto, G.; Widjaja, S.; Sutiono, S. J. Liq. Chromatogr. Relat. Technol. 1999, 22(1), 143-152.

[23]. Morin, N.; Guillaume, Y. C.; Rouland, J. C. Chromatographia 1998, 48(56), 388-394.

[24]. Han, J.; Zeng, H. J.; Tang, H. F. Yaowu Fenxi Zazhi 1997, 17(1), 9-11.

[25]. Kobylinska, M.; Kobylinska, K.; Sobik, B. J. Chromatogr. B: Biomed. Appl. 1996, 685(1), 191-195.

[26]. Roychowdhury, U.; Das, S. K. J. Aoac. Int. 1996, 79(3), 656-658.

[27]. Zhang, S.; Luo, S.; Zhang, F.; Cai, H.; Yin, W. Yaowu Fenxi Zazhi 1993, 13(3), 198-199.

[28]. Tyler, T. A.; Genzale, J. A. J. Assoc. Off. Ana. Chem. 1989, 72(3), 442-444.

[29]. Selinger, K.; Matheou, D.; Hill, H. M. J. Chromatogr. 1988. 434, 259-264.
[30]. Hosotsubo, H. Chromatographia 1988, 25(8), 717-720

[31]. Blanco, M.; Coello, J.; Iturriaga, H.; Maspoch, S.; Villegas, N. Analyst 1999, 124(6), 911-915.

[32]. Bonazzi, D.; Andrisano, V.; Gatti, R.; Cavrini, V. J. Pharm. Biomed. Anal. 1995, 13(11), 1321-1329.

[33]. Nikolic, K.; Medenica, M.; Bogavac, M.; Arsenijevic, L. Farmaco 1991, 46(4), 623-626.

[34]. Walash, M. I.; Zakhari, N. A.; Rizk, M.; Toubar, S. Farmaco 1987, 42(3), 81-90.

[35]. Rizk, M.; Zakhari, N.; Toubar, S.; Walash, M. I. Acta Pharm. Fenn. 1984, 93(3), 129-134.

[36]. Zuo, Z. H.; Tang, S. F. Yaowu Fenxi Zazhi 2010, 30(8), 1516-1519.

[37]. Chauhan, V.; Conway, B. Chromatographia 2005, 61(11-12), 555-559.

[38]. Zuo, Z. H.; Zhou, J. M.; Zuo, W. U. Yaowu Fenxi Zazhi 2004, 24(4), 420421.

[39]. Hajkova, R.; Solich, P.; Dvorak, J.; Sicha, J. J. Pharm. Biomed. Anal. 2003 32(4-5), 921-927.

[40]. Lemus-Gallego, J. M.; Perez-Arroyo, J. Anal. Bioanal. Chem. 2002 374(2), 282-288.

[41]. Ku, Y. R.; Wen, K. C.; Ho, L. K.; Chang, Y. S. Yaowu Shipin Fenxi 1999 $7(2), 123-130$.

[42]. Reubsaet, J. L. E.; Vieskar, R. J. Chromatogr. A. 1999, 841(2), 147-154.

[43]. Valenta, C.; Janout, H. J. Liq. Chromatogr. 1994, 17(5), 1141-1146.

[44]. Bhounsule, G. J.; Gorule, V. S.; Patil, G. V. Indian Drugs 1992, 29(13), 594-597.

[45]. Hailey, D. M.; Lea, A. R. J. Assoc. Off. Ana. Chem. 1981, 64(4), 870-874.

[46]. Mousa, B. A.; El-Kousy, N. M.; El-Bagary, R. I.; Mohamed, N. G. Chem. Pharm. Bull. 2008, 56(2), 143-149.

[47]. Di-Pietra, A. M.; Andrisano, V.; Gotti, R.; Cavrini, V. J. Pharm. Biomed. Anal. 1996, 14(8-10), 1191-1199.

[48]. Shaikh, S.; Muneera, M. S.; Thusleem, O. A.; Tahir, M.; Kondaguli, A. V. J. Chromatogr. Sci. 2009, 47(2), 178-183.

[49]. Sahasranaman, S.; Tang, Y. F.; Biniasz, D.; Hochhaus, G. J. Chromatogr. B. 2005, 819(1), 175-179.

[50]. Wulandari, L.; Sia, T. K.; Indrayanto, G. Liq. Chromatogr. Relat. Technol. 2003, 26(1), 109-117.

[51]. Teng, X. W.; Foe, K.; Brown, K. F.; Cutler, D. J.; Davies, N. M. J. Pharm Biomed. Anal. 2001, 26(2), 313-319.

[52]. Spangler, M. Supelco. Rep. 1994, 13(2), 12-13.

[53]. The European Agency for the Evaluation of Medical Products, ICH Topic Q2B Note for Guidance on Validation of Analytical Procedures, Methodology GPMP/ICH/281/95, 1996.

[54]. The United States Pharmacopeial Convention, Thirty-Fourth Revision, NF29, 2011.

[55]. British pharmacopeia. The stationary office, medical and pharmaceutical substances, London, 2011. 